\title{
Influence of emulsion properties on the microencapsulation of orange essential oil by spray drying
}

\author{
Paula A. O. Carmona ${ }^{\mathrm{a}}$, Renata V. Tonon ${ }^{\mathrm{a}, \mathrm{b}}$ and Miriam D. Hubinger ${ }^{\mathrm{a}}$ \\ ${ }^{a}$ Department of Food Engineering, Faculty of Food Engineering, University of Campinas, Campinas, Brazil \\ (paanosca@fea.unicamp.br, mhub@fea.unicamp.br) \\ ${ }^{b}$ Embrapa Food Technology, Rio de Janeiro, Brazil (renata.tonon@ctaa.embrapa.br)
}

\begin{abstract}
This work aimed to study the effect of emulsion properties on the microencapsulation of orange essential oil by spray drying. The study was performed using a $2^{3}$ central composite design, where the independent variables were the total solid content (0-30\%), the ratio of oil/total solids (0-30\%) and the homogenization pressure used for emulsification (0-1000 bar). Whey protein concentrate and $20 \mathrm{DE}$ maltodextrin, mixed in a 1:3 ratio, were used as wall materials. The emulsions were first prepared by blending the oil and the wall solution, using a rotor-stator blender; they were further emulsified using a high pressure homogenizer. All emulsions were characterized for viscosity and droplets mean diameter. Microencapsulation was performed in a laboratory scale spray dryer and particles were characterized for total and surface oil content. From these results, encapsulation efficiency and oil retention were calculated and analyzed as responses, being used for process optimization. In general, the best process responses were obtained at moderate homogenization pressures (400-650 bar), in which emulsions had the smallest droplet diameters. Higher solid content and lower oil concentration resulted in higher encapsulation efficiency and greater flavor retention, which was attributed to the higher viscosity and smaller droplet size presented by the emulsions produced under these conditions.
\end{abstract}

Keywords: microencapsulation, emulsion properties, high pressure homogenization, spray drying, whey protein concentrate, maltodextrin.

\section{INTRODUCTION}

The essential oil of citric fruits is a volatile oily liquid that represents its most important aromatic fraction and is composed of a complex mixture of compounds, especially terpenes, sesquiterpenes, alcohols, ketones, phenols, acids, aldehydes and esters. However, it is highly susceptible to oxidative and chemical degradation [1].

Microencapsulation is a process widely used to retain and protect chemically reactive and volatile oils. The most common technique to accomplish the microencapsulation of flavors is by spray drying, which enables the transformation of a liquid feed into dried particles. Microencapsulation by spray drying includes the preparation of the dispersion or emulsion to be processed, the homogenization of this dispersion and the spray within the drying chamber [2]. During spray drying, the temperature of the atomized droplets slightly increases, while their water content decreases. Due to the differences between water and volatiles molecular weights, the reduction in diffusivity of volatiles is greater than that of water [3], thus allowing good retention. The emulsion stability is an important factor to be considered for flavor encapsulation, since they are generally water-insoluble [4]. The aim of emulsification is to produce droplets as small as possible and various techniques can be used for this purpose. High homogenization pressure is widely used to emulsify, disperse, homogenize and to reduce droplets size, in order to obtain emulsions stables to coalescence [5].

Due to their different chemical groups, amphiphilic properties, ability to interact with various kinds of substances, big molecular weight and flexible molecular chain, the proteins have excellent encapsulating properties [6]. Whey protein acts as a barrier against the oxidation of microencapsulated orange oil and limits the limonene oxidation, providing better protection than the traditional flavor carriers, which are more permeable to oxygen [7]. This protein acts as an emulsifier and film-forming agent, while carbohydrates serve as the matrix forming material [8].

Most studies reported in the literature about flavor encapsulation do not evaluate the effect of emulsion droplet size on the encapsulation efficiency and oil retention. Recently, the modification of emulsion 
properties before drying has been suggested as an alternative in the microencapsulation process, since the flavor retention can be improved by reducing the emulsion droplets mean diameter during emulsification [5]. Thus, the objective of this work was to evaluate the influence of total solid content (10-30\%), oil concentration in relation to solids (10 to 30\%) and homogenization pressure (0 to 1000 bar) on the microencapsulation of orange oil by spray drying, using a mixture of whey protein concentrate and maltodextrin DE 20 (1:3) as wall material. The emulsion properties (droplet size and viscosity), as well as the encapsulation efficiency and oil retention, were analysed as responses.

\section{MATERIALS \& METHODS}

\section{Materials}

The orange essential oil was kindly supplied by Citrosuco FISCHER S/A Com. e Ind. Agr. (Limeira, Brazil), with the following specifications: density at $25^{\circ} \mathrm{C}: 0.843 \mathrm{~g} / \mathrm{cm} 3$, refractive index at $20^{\circ} \mathrm{C}: 1.4728$; aldehydes: $1.74 \%$.

Maltodextrin MOR-REX ${ }^{\circledast} 1920(17 \leq \mathrm{DE} \leq 19.9)$ was kindly provided by Corn Products (Mogi-Guaçu, Brazil) and whey protein concentrate LACPRODAN ${ }^{\circledR} 80$ (80-84\% protein on dry basis) by Arla Foods Ingredients (São Paulo, Brazil).

To prevent foam formation during the hydrodistillation process, the anti-foaming SILAEX SQ 4330 was used (Silaex ${ }^{\circledR}$ Química Ltda., São Paulo, Brazil).

\section{Emulsions preparation}

The wall materials were dispersed in deionized water at room temperature and mixed until completely dissolution, 24 hours before emulsification. A pre-emulsion was formed by mixing the wall material and the orange oil, using a rotor-stator homogenizer (Ultra-turrax IKA T18 Basic, Germany) at 14,000 rpm for 5 min. Then, a secondary emulsion was formed, using a high pressure homogenizer in two stages (NS1001L2KPANDA2K, Niro Soave S.P.A., Parma, Italy). The pressure in the first stage ranged from 200 to 1000 bar and in the second stage it was 50 bar.

\section{Emulsions characterization}

Droplets mean diameter

The determination of droplets mean diameter was made by optical microscopy using an optical microscope Jenaval (Carl Zeiss, Oberkochen, Germany). The Sauter mean diameter $\left(\mathrm{D}_{3,2}\right)$ was calculated by measuring 500 droplets using the image processor system EDN-2 1.25x.

\section{Emulsion viscosity}

Emulsion viscosity was determined by flow curves (shear stress $\times$ shear rate), using a controlled stress rheometer Physica MCR301 (Anton Paar, Graz, Austria) at $25^{\circ} \mathrm{C}$, with stainless steel plate-plate geometry of $75 \mathrm{~mm}$ diameter and gap of $0.5 \mathrm{~mm}$. Three flow curves (up, down and up-cycles) were obtained through shear stress intervals corresponding to a strain rate of 0 to $300 \mathrm{~s}^{-1}$. Rheograms were analyzed using empirical models and the viscosity of the samples was calculated as the ratio between shear stress and shear rate.

\section{Microencapsulation by spray drying}

The process was conducted in a laboratory scale spray dryer Labmaq MSD 1.0 (Ribeirão Preto, Brazil) with a drying chamber of $500 \mathrm{~mm} \times 150 \mathrm{~mm}$ and a double fluid nozzle atomizer with $1.2 \mathrm{~mm}$ diameter. Feeding was done through a peristaltic pump, the inlet and outlet air temperatures were maintained at $190^{\circ} \mathrm{C}$ and 106 $\pm 4^{\circ} \mathrm{C}$, respectively, with an emulsion flow rate of $0.8 \mathrm{~L} / \mathrm{h}$. The drying air flow was $36 \mathrm{~m}^{3} / \mathrm{h}$, the compressed air pressure was $0.25 \mathrm{MPa}$ and the compressed air flow was $2.4 \mathrm{~m}^{3} / \mathrm{h}$.

A rotatable central composite design was used considering three independent variables: total solids content (10-30\%), oil concentration in relation to solids (10 to 30\%) and homogenization pressure (0-1000 bar). Five levels of each variable were chosen for the experiments, including the central point and two axial points for a total of 17 tests (Table 1). The following polynomial equation was fitted to data:

$y=\beta_{0}+\beta_{1} x_{1}+\beta_{2} x_{2}+\beta_{3} x_{3}+\beta_{11} x_{1}^{2}+\beta_{22} x_{2}^{2}+\beta_{33} x_{3}^{2}+\beta_{12} x_{1} x_{2}+\beta_{13} x_{1} x_{3}+\beta_{23} x_{2} x_{3}$

Where $\beta_{n}$ are the constant regression coefficients; $y$ is the response and $x_{1}, x_{2}$ and $x_{3}$ are the coded independent variables (total solids, oil concentration and homogenization pressure respectively). 
The analysis of variance (ANOVA), test for the lack of fit, determination of $\mathrm{R}^{2}$ and the generation of threedimensional graphs were carried out using the Statistica 7.0 software (StatSoft, Tulsa, USA).

\section{Powder analysis}

\section{Total oil content and oil retention}

The oil retained in the microencapsulated powders was determined in triplicate by hydrodistillation in a Clevenger apparatus, using a method described by Bhandari et al. [9], with some modifications. About $5 \mathrm{~g}$ of powder were dissolved in $150 \mathrm{~mL}$ of distilled water in a round bottom flask of $500 \mathrm{~mL}$, with 1 drop of antifoam. The Clevenger was placed on top of the flask and a condenser with circulating water at $5^{\circ} \mathrm{C}$ was placed on the Clevenger. Distillation was performed for 1 hour, and the volume of distilled oil directly read in Clevenger and multiplied by the density of orange essential oil $(0.843 \mathrm{~g} / \mathrm{mL})$, in order to calculate the mass of oil recovered. The oil retention was calculated according to Equation (2):

$$
\text { Oil } \operatorname{Re} \text { tention }=\frac{T O}{I O} \times 100
$$

Where $T O$ is the powder total oil and $I O$ is the initial oil added to the emulsion.

\section{Microencapsulation efficiency}

The surface oil was determined according to the method described by Bhandari et al. [10], with some modifications. Twenty milliliters of hexane were added to $5 \mathrm{~g}$ of powder and this mixture was stirred for ten minutes at room temperature. The mixture was filtered through a Whatman filter paper number 1 and the residue collected in the filter was washed again with ten milliliters of hexane. Next, solvent was evaporated in a vacuum oven at $40^{\circ} \mathrm{C}$ for 5 minutes. The amount of non-encapsulated oil was determined by the mass of oil, after evaporation of hexane and microencapsulation efficiency was calculated from Equation (3) [11]:

$$
\text { EncapsulationEfficiency }(\%)=\frac{T O-S O}{I O} \times 100
$$

Where $S O$ is the powder surface oil.

\section{RESULTS \& DISCUSSION}

Table 1 shows the results for the different responses evaluated by experimental design.

Table 1. Responses obtained for the 17 trials of the experimental design.

\begin{tabular}{l|l|l|l|l|l|l|l}
\hline Trials & $\begin{array}{l}\text { Total } \\
\text { solids }(\boldsymbol{\%})\end{array}$ & $\begin{array}{l}\text { Oil/Total } \\
\text { solids }(\%)\end{array}$ & $\begin{array}{l}\text { Homogenization } \\
\text { pressure (bar) }\end{array}$ & $\mathbf{D}_{\mathbf{3 , 2}}(\boldsymbol{\mu m})$ & $\begin{array}{l}\text { Viscosity } \\
(\mathbf{m P a} . \mathbf{s})\end{array}$ & $\begin{array}{l}\text { Encapsulation } \\
\text { efficiency }(\boldsymbol{\%})\end{array}$ & $\begin{array}{l}\text { Oil retention } \\
(\boldsymbol{\%})\end{array}$ \\
\hline $\mathbf{1}$ & $14(-1)$ & $14(-1)$ & $200(-1)$ & $0.81 \pm 0.17$ & $2.20 \pm 0.00$ & $72.69 \pm 0.03$ & $73.23 \pm 0.03$ \\
\hline $\mathbf{2}$ & $26(+1)$ & $14(-1)$ & $200(-1)$ & $0.98 \pm 0.33$ & $5.90 \pm 0.00$ & $71.66 \pm 0.01$ & $72.16 \pm 0.58$ \\
\hline $\mathbf{3}$ & $14(-1)$ & $26(+1)$ & $200(-1)$ & $0.71 \pm 0.34$ & $1.93 \pm 0.00$ & $49.86 \pm 0.02$ & $50.31 \pm 0.50$ \\
\hline $\mathbf{4}$ & $26(+1)$ & $26(+1)$ & $200(-1)$ & $0.67 \pm 0.22$ & $5.73 \pm 0.00$ & $55.24 \pm 0.02$ & $55.64 \pm 0.41$ \\
\hline $\mathbf{5}$ & $14(-1)$ & $14(-1)$ & $800(+1)$ & $1.09 \pm 0.32$ & $2.20 \pm 0.00$ & $72.46 \pm 0.04$ & $72.93 \pm 0.63$ \\
\hline $\mathbf{6}$ & $26(+1)$ & $14(-1)$ & $800(+1)$ & $1.11 \pm 0.34$ & $6.00 \pm 0.00$ & $71.37 \pm 0.14$ & $71.80 \pm 0.27$ \\
\hline $\mathbf{7}$ & $14(-1)$ & $26(+1)$ & $800(+1)$ & $1.58 \pm 0.55$ & $1.70 \pm 0.00$ & $59.32 \pm 0.01$ & $59.66 \pm 0.17$ \\
\hline $\mathbf{8}$ & $26(+1)$ & $26(+1)$ & $800(+1)$ & $1.50 \pm 0.60$ & $5.03 \pm 0.00$ & $51.29 \pm 0.01$ & $51.66 \pm 3.16$ \\
\hline $\mathbf{9}$ & $10(-1,68)$ & $20(0)$ & $500(0)$ & $1.06 \pm 0.49$ & $1.60 \pm 0.00$ & $60.41 \pm 0.06$ & $60.82 \pm 0.50$ \\
\hline $\mathbf{1 0}$ & $30(+1,68)$ & $20(0)$ & $500(0)$ & $1.04 \pm 0.38$ & $8.50 \pm 0.00$ & $74.07 \pm 0.01$ & $74.37 \pm 0.66$ \\
\hline $\mathbf{1 1}$ & $20(0)$ & $10(-1,68)$ & $500(0)$ & $0.52 \pm 0.20$ & $3.30 \pm 0.00$ & $84.26 \pm 0.01$ & $84.98 \pm 0.11$ \\
\hline $\mathbf{1 2}$ & $20(0)$ & $30(+1,68)$ & $500(0)$ & $1.27 \pm 0.53$ & $3.03 \pm 0.00$ & $58.63 \pm 0.02$ & $58.96 \pm 0.22$ \\
\hline $\mathbf{1 3}$ & $20(0)$ & $20(0)$ & $0(-1,68)$ & $1.48 \pm 0.75$ & $3.30 \pm 0.00$ & $59.16 \pm 0.02$ & $60.15 \pm 0.03$ \\
\hline $\mathbf{1 4}$ & $20(0)$ & $20(0)$ & $1000(+1,68)$ & $1.71 \pm 0.90$ & $3.40 \pm 0.00$ & $68.98 \pm 0.01$ & $69.41 \pm 0.04$ \\
\hline $\mathbf{1 5}$ & $20(0)$ & $20(0)$ & $500(0)$ & $0.89 \pm 0.38$ & $3.40 \pm 0.00$ & $69.59 \pm 0.06$ & $69.95 \pm 0.04$ \\
\hline $\mathbf{1 6}$ & $20(0)$ & $20(0)$ & $500(0)$ & $0.69 \pm 0.21$ & $3.50 \pm 0.00$ & $69.31 \pm 0.09$ & $69.68 \pm 0.79$ \\
\hline $\mathbf{1 7}$ & $20(0)$ & $20(0)$ & $500(0)$ & $0.94 \pm 0.43$ & $3.43 \pm 0.00$ & $74.9 \pm 0.030$ & $75.30 \pm 0.70$ \\
\hline
\end{tabular}


Table 2 shows the regression coefficients for the coded second-order polynomial equation, the $\mathrm{F}$ values and the determination coefficients $\left(\mathrm{R}^{2}\right)$. Some non-significant terms were eliminated and the resulting equations were tested for adequacy and fitness by the analysis of variance (ANOVA). The fitted models were suitable, showing significant regression, low residual values, no lack of fit and satisfactory determination coefficients.

Table 2. Coded second-order regression coefficients for the obtained responses.

\begin{tabular}{l|l|l|l|l}
\hline Coefficient & $\mathbf{D}_{\mathbf{3}, \mathbf{2}}(\boldsymbol{\mu m})$ & Viscosity $(\mathbf{m P a} . \mathbf{s})$ & Encapsulation efficiency $(\boldsymbol{\%})$ & Oil retention $(\boldsymbol{\%})$ \\
\hline$\beta_{0}$ & 0.88 & 3.39 & 68.29 & 70.81 \\
\hline$\beta_{1}$ & N.S. & 1.92 & N.S. & N.S. \\
\hline$\beta_{2}$ & 0.13 & -0.18 & -8.46 & -8.54 \\
\hline$\beta_{3}$ & 0.18 & N.S. & N.S. & N.S. \\
\hline$\beta_{11}$ & N.S. & 0.57 & N.S. & -2.17 \\
\hline$\beta_{22}$ & N.S. & -0.099 & N.S. & N.S. \\
\hline$\beta_{33}$ & 0.23 & N.S. & -2.76 & -3.16 \\
\hline$\beta_{12}$ & N.S. & N.S. & N.S. & N.S. \\
\hline$\beta_{13}$ & N.S. & N.S. & N.S. & N.S. \\
\hline$\beta_{23}$ & 0.16 & N.S. & N.S. & N.S. \\
\hline$R^{2}$ & 0.81 & 0.99 & 0.75 & 0.80 \\
\hline$F$ & 12.83 & 285.05 & 21.57 & 17.24 \\
\hline N.S. N & & &
\end{tabular}

N.S. Non-significant $(\mathrm{p}>0.10)$.

\section{Droplets mean diameter}

Figure 1 shows the effect of the independent variables on the droplets mean diameter and or viscosity of the emulsions studied.
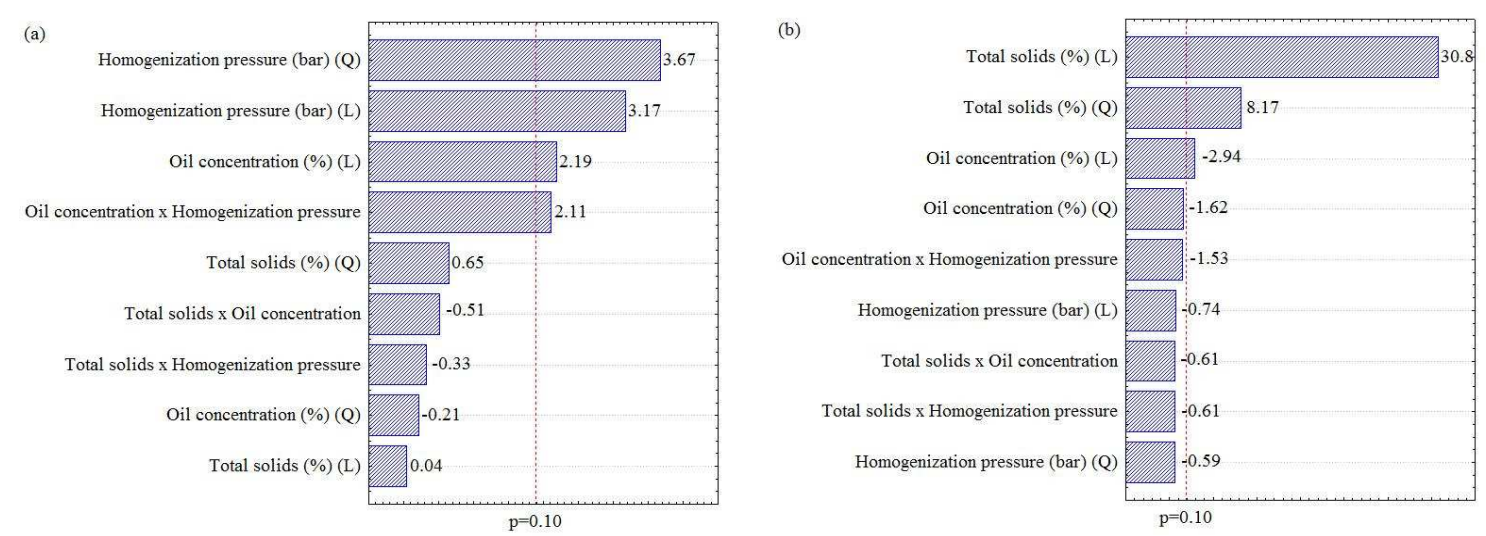

Figure 1. Effect of independent variables on the: (a) droplets mean diameter and (b) viscosity of the emulsions studied.

The emulsion droplets mean diameter ranged from 0.52 to $1.71 \mu \mathrm{m}$. Homogenization pressure was the variable that most affected this response. When homogenization pressures below 500 bar were used, the increase in pressure led to a reduction on droplet size. On the other hand, when higher pressures were used, the increase in the homogenization pressure resulted in higher droplets size. For example, emulsions homogenized at 1000 bar resulted in a $\mathrm{D}_{3,2}$ of $1.71 \mu \mathrm{m}$, while the emulsions homogenized only by the rotorstator had a $\mathrm{D}_{3,2}$ of $1.48 \mu \mathrm{m}$. This phenomenon in which the droplet size increases with increasing energy emulsification is termed as over-processing and can be attributed to the underperformance of emulsifiers and to an increase in the droplets Brownian motion, resulting in higher probability of collision and coalescence [12]. In general, all emulsions homogenized at pressures between 200 and 500 bar showed mean diameters lower than $1 \mu \mathrm{m}$.

Emulsion droplet size also increased with increasing oil content, indicating that when low oil contents are used, the protein had the ability to interact in interface oil/water, completely covering the oil droplets and preventing their coalescence during high pressure homogenization. Total solid content did not have significant influence on droplets mean diameter. 


\section{Emulsions viscosity}

All the emulsions presented flow index values to the Power Law model very close to 1 , so the samples were considered as Newtonian fluids.

According to Table 2, total solid content was the variable that most influenced emulsions viscosity, and the increase in total solids concentration from 10 to $30 \%$ resulted in an increase in viscosity from 0.0016 to 0.0085 Pa.s. High viscosity in the initial emulsion increased volatiles retention due to reduced droplets movement, favoring a rapid matrix formation and limiting the oil diffusion through the wall material [8].

Higher oil concentrations resulted in lower viscosity, which can be attributed to the lower amount of wall material available. Hogan et al. [13], encapsulating soybean oil in sodium caseinate and carbohydrates of different DE, also observed a decrease in viscosity and encapsulation efficiency with the increase in oil/solid ratio, which was associated to the lower protein content.

Regarding the homogenization pressure, there was no significant effect of this variable on the emulsions viscosity.

\section{Powder analysis}

The response surfaces obtained for encapsulation efficiency and oil retention are shown in Figure 2.
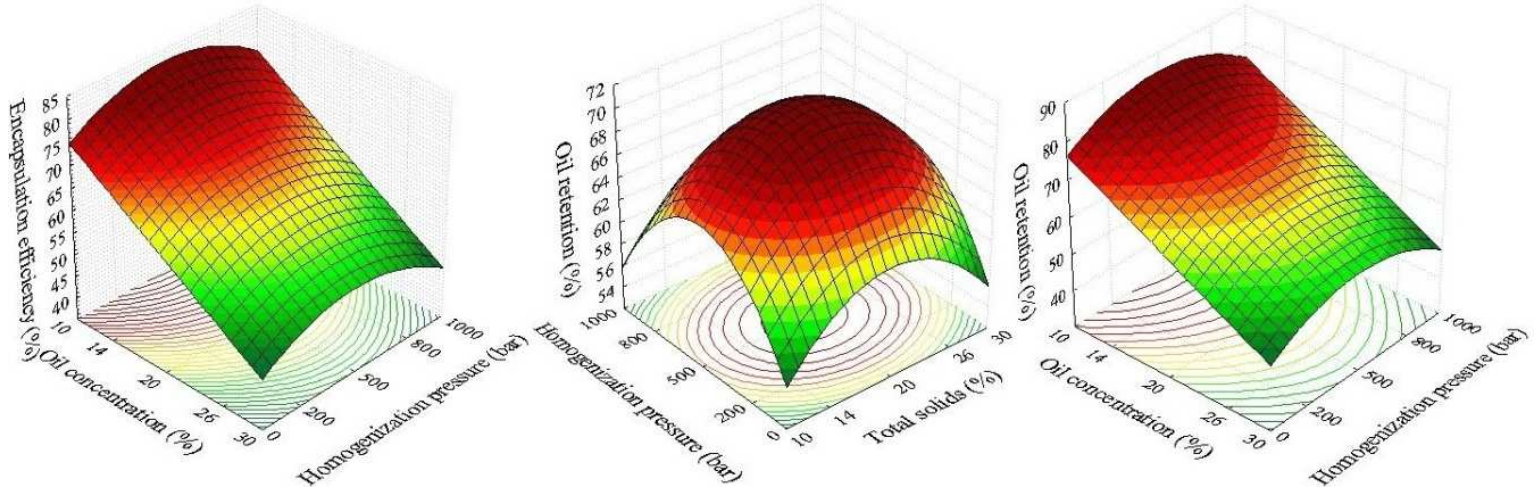

Figure 2. Response surfaces for (a) Encapsulation efficiency of particles produced at solids of 20\%; (b) Oil retention of particles produced at oil concentration of $20 \%$ and (c) Oil retention of particles produced at total solids of $20 \%$.

\section{Encapsulation efficiency}

According to Tables 1 and 2, the encapsulation efficiency ranged between 49.86 and $84.26 \%$ and was significantly influenced by oil content and homogenization pressure.

Oil concentration was the variable that most affected the encapsulation efficiency, showing a negative effect on this response. High concentrations of oil in relation to solids (26 to 30\%) resulted in lower encapsulation efficiencies. This result may be related to the fact that the emulsions containing higher oil concentrations have lower amount of encapsulating agent to stabilize them.

The homogenization pressure had a positive effect on the encapsulation efficiency, when homogenization pressures up to 500 bar were used. Above this value, the increase of homogenization pressure led to a reduction of encapsulation efficiency. This result is related to the emulsion droplet size, as discussed above. According to Jafari et al. [14], the higher surface oil in the particles produced from emulsions with larger droplets can be attributed to the droplets breakdown during atomization, resulting in lower encapsulation efficiency.

\section{Oil retention}

Oil retention ranged between 50.31 and $84.98 \%$ and all the variables had significant effect on this response. The oil retention was maximized at a total solid content higher than $20 \%$, oil in relation to solids lower than $14 \%$ and homogenization pressure between 400 and 650 bar.

Higher solid content in the emulsions increased the oil retention, mainly by reducing the time required to form a semipermeable membrane on the surface of the dried particles. Furthermore, the use of higher solid content increased the emulsion viscosity, preventing the droplets movements and promoting a rapid crust formation around the particles [15]. 
A reduction in oil retention was observed when higher oil concentrations were used, which may be due to an insufficient amount of wall material to form a sufficiently strong structural matrix surrounding the emulsion droplets.

Finally, high homogenization pressures (1000 bar) resulted in an increase on emulsion droplet size $(1.71 \mu \mathrm{m})$ and, consequently, in the reduction of oil retention $(69.41 \%)$, which may be related to the high rate of droplets coalescence of the emulsions homogenized at high pressures, as discussed above. Floury et al. [16] reported that the structure degradation of high molecular weight compounds such as proteins and gums, occurs at high pressures due to increasing temperatures and high shear stresses. Changes in the molecular weight of a polymer also affect its functional attributes, such as emulsifying and stabilizing properties.

\section{CONCLUSION}

Encapsulation efficiency was influenced by oil concentration and homogenization pressure, while the oil retention was affected by total solids, oil concentration and homogenization pressure. These results were related to the emulsions droplet size and viscosity. The conditions selected as the most suitable for the microencapsulation of orange essential oil were: total solids content greater than $20 \%$, oil concentration below $15 \%$ and homogenization pressure between 400 and 650 bar. The process optimization as a function of total solid content, oil concentration and homogenization pressure, allows the production of high quality particles, with higher amount of total oil and lower amount of surface oil, i.e., less susceptible to oxidation.

\section{ACKNOWLEDGEMENT}

The authors are grateful to FAPESP (process 2009/54137-1), CAPES and CNPq for the financial support.

\section{REFERENCES}

[1] Ananaram S., \& Reineccius G.A. 1986. Stability of encapsulated orange peel oil. Food Technology, 40(11), 88-93.

[2] Gharsallaoui A., Roudaut G., Chambin O., Voilley A., \& Saurel, R. 2007. Applications of spray-drying in microencapsulation of food ingredients: An overview. Food Research International, 40(9), 1107-1121.

[3] Bylaitë E., Venskutonis P.R. \& Mapdpierienë R. 2001. Properties of caraway (Carum carvi L.) essential oil encapsulated into milk protein-based matrices. European Food Research and Technology, 212, 661-670.

[4] McClements D. J. 2005. Food emulsions: Principles, practice, and techniques (2nd ed). Boca Raton: CRC Press, $609 \mathrm{p}$.

[5] Kaushik V. \& Roos Y.H. 2007. Limonene encapsulation in freeze-drying of gum Arabic-sucrose-gelatin systems. Lebensmittel-Wissenschaft und-Technologie, 40, 1381-1391.

[6] Madene, A., Jacquot M., Scher J. \& Desobry S. 2006. Flavour encapsulation and controlled release - a review. International Journal of Food Science and Technology, 41(1), 1-21.

[7] Charve J. \& Reineccius G.A. 2009. Encapsulation Performance of Proteins and Traditional Materials for Spray Dried Flavors. Journal of Agricultural and Food Chemistry, 57(6), 2486-2492.

[8] Sheu T.Y. \& Rosenberg M. 1998. Microstructure of microcapsules consisting of whey proteins and carbohydrates. Journal of Food Science, 63(3), 491-494.

[9] Bhandari B.R., Dumoulin E.D., Richard H.M.J., Noleau I. \& Lebert A.M. 1992. Flavor encapsulation by spray drying: Application to citral and linalyl acetate. Journal of Food Science, 57(1), 217-221.

[10] Bhandari B.R., D'arcy B.R. \& Bich L.L.T. 1998. Lemon oil to $\beta$-cyclodextrin ratio effect on the inclusion efficiency of $\beta$-cyclodextrin and the retention of oil volatiles in the complex. Journal of Agricultural and Food Chemistry, 46, 1494-1499.

[11] Baranauskiene R., Bylait E., Ukauskait J. \& Venskutonis R.P. 2007. Flavor retention of Peppermint (Mentha piperita L.) essential oil spray-dried in modified starches during encapsulation and storage, 55(8), 3027-3036.

[12] Jafari S.M., He Y. \& Bhandari B. 2006. Nano-emulsion production by sonication and microfluidization - a comparison. International Journal of Food Properties, 9(3), 475-485.

[13] Hogan S.A., McNamee B.F., O’Riordan E.D. \& O'Sullivan M. 2001b. Emulsification and microencapsulation properties of sodium caseinate/carbohydrate blends. International Dairy Journal, 11, 137-144.

[14] Jafari S.M., Assadpoor E., He Y. \& Bhandari B. 2008. Encapsulation efficiency of food flavours and oils during spray drying. Drying Technology, 26(7), 816-835.

[15] Jafari, S. M., Assadpoor E., He Y. \& Bhandari B. 2008. Re-coalescence of emulsion droplets during high-energy emulsification. Food Hydrocolloids, 22, 1191-1202.

[16] Floury J., Desrumaux A., Axelos M.A.V. \& Legrand J. 2003. Effect of high pressure homogenization on methylcellulose as food emulsifier. Journal of Food Engineering, 58, 227-238. 